\title{
O “APELO DIRETO” ESTÁ ALTERANDO O FORMATO DE COMUNICAÇÃO DOS PARTIDOS POLÍTICOS: AS REDES SOCIAIS GANHAM ESPAÇO E REDUZEM AS ESTRUTURAS TRADICIONAIS DE MEDIAÇÃO
}

THE DIRECT APPEAL IS CHANGING THE FORMAT OF COMMUNICATION OF POLITICAL PARTIES:

SOCIAL NETWORKS GAIN SPACE AND REDUCE TRADITIONAL MEDIATION STRUCTURES

LA APELACIÓN DIRECTA ESTÁ CAMBIANDO EL FORMATO DE COMUNICACIÓN DE LOS PARTIDOS POLITIICOS: LAS REDES SOCIALES GANAN ESPACIO Y REDUCEN LAS ESTRUCTURAS DE MEDIACIÓN TRADICIONALES

Fernando Biffignandi

RESUMO: Realizada em seu gabinete na Universidade de Perugia, Itália, a entrevista com Paolo Mancini é um importante documento que nos instiga a pensar sobre um novo modelo de comunicação baseado na relação direta entre fonte e usuário, entre o político e o eleitor, um reflexo claro dos processos de transparência da informação. Mancini reforça que esta nova tendência de comunicação se aplica aos partidos políticos alterando algumas práticas tradicionais dentro das sociedades democráticas. Ao interagir diretamente com o eleitor, o político abre uma nova via comunicativa, um novo canal sem a intermediação tradicional. Mancini classifica este fenômeno como "apelo direto", um estilo populista que permite ao político adaptar-se às ideias, linguagem e valores já compartilhados pelo cidadão. Para Mancini as administrações públicas são

ORCID: http://orcid.org/oooo-0o01-7442-9043. E-mail: biffignandi@yahoo.com 
compelidas a publicar os dados, não apenas para cumprir a lei, mas porque indivíduos têm a possibilidade de acessar e fazer circular a informação através da rede.

Palavras-chave: Paolo Mancini. Comunicação política. Transparência na informação

ABSTRACT: The interview given in his office at the University of Perugia, Italy by Paolo Mancini is an important document that instigates us to think about a new model of communication based on the direct relationship between source and user, between the politician and the voter, a clear reflection of the processes of information transparency. Mancini reinforces that this new trend of communication applies to political parties by changing some traditional practices within democratic societies. By interacting directly with the voter the politician opens a new communication path, a new channel without traditional intermediation. Mancini classifies this phenomenon as a "direct appeal", a populist style that allows the politician to adapt to the ideas, language and values already shared by the citizen. For Mancini public administrations are compelled to publish the data, not only to comply with the law, but because individuals have the possibility to access and circulate the information through the network.

Keywords: Paolo Mancini. Political communication. Information transparency.

RESUMEN: En su oficina de la Universidad de Perugia, Italia, la entrevista con Paolo Mancini es un documento importante que nos anima a pensar en un nuevo modelo de comunicación basado en la relación directa entre la fuente y el usuario, entre el político y el votante. Clara reflexión de los procesos de transparencia de la información. Mancini subraya que esta nueva tendencia de comunicación se aplica a los partidos políticos al alterar algunas prácticas tradicionales dentro de las sociedades democráticas. Al interactuar directamente con el votante, el político abre un nuevo camino comunicativo, un nuevo canal sin la intermediación tradicional. Mancini clasifica este fenómeno como un atractivo directo, un estilo populista que permite al político adaptarse a las ideas, el lenguaje y los valores que ya comparte el ciudadano. Para Mancini, las administraciones públicas están obligadas a publicar datos, no solo para cumplir con la ley, sino porque los individuos tienen la capacidad de acceder y circular información a través de la red.

PALABRAS CLAVE: Paolo Mancini. La comunicación política. Transparencia en la información. 


\section{Entrevista com Paolo Mancini ${ }^{2}$ realizada na Universidade de Estudos de Perugia - Itália, em maio de 2018}

Revista Famecos - O Senhor escreveu em Quaderni di sociologia (2002) que as razões responsáveis pela evolução da comunicação pública são a crescente conscientização dos direitos de cidadania, o desenvolvimento do estado de bem-estar social e suas transformações, o nascimento de uma arena de comunicação de massa competitiva e a inovação tecnológica. Considerando o aumento de usuários da internet, como as redes sociais podem reduzir as desigualdades sociais através de uma maior participação dos cidadãos?

Paolo Mancini - Sem dúvida, eles podem fazê-lo através da transparência, através do conhecimento dos atos dos governantes. A velocidade com que a mídia evolui atingiu níveis incrivelmente altos, mas muitos potenciais ainda são desconhecidos. A história da comunicação de massa passa por um processo contínuo de crescentes transformações, com períodos de escassez e / ou abundância. Em meados da década de 1990 os recursos de comunicação e circulação (mídia e mensagem) eram limitados pela baixa capacidade de transmissão, um quadro que mudou ao longo dos anos, após um desenvolvimento tecnológico impetuoso. No entanto, na área da cidadania a comunicação promovida pelo órgão público evoluiu lentamente ainda que a evolução do panorama tecnológico tenha nos permitido identificar mudanças significativas na estrutura e na elaboração do sistema de comunicação de massa. Porém, ainda hoje, existem países onde o acesso a novas tecnologias é limitado, reduzindo ou impedindo o acesso à informação. O certo é que a comunicação desempenha, cada vez mais, o papel de garantir a transparência como obrigação social, possibilitando que os atos administrativos do governo sejam públicos, tornando-se uma poderosa ferramenta de participação e controle sobre o trabalho das administrações públicas. Hoje, os cidadãos estão se tornando mais conscientes de seus direitos e as novas tecnologias tornam obrigatória a comunicação, sobretudo, através do acesso direto às fontes de informação.

Faço referência ao que Max Weber disse sobre a transparência como uma ferramenta de controle e não há dúvida de que hoje o desenvolvimento da internet garante maiores possibilidades para essa transparência e, portanto, para o controle.

\footnotetext{
2 Paolo Mancini, italiano, professor titular de Sociologia das Comunicações no Dipartimento di Scienze Politiche dell'Università degli Studi di Perugia, Itália. Seus trabalhos concentram-se na relação entre o sistema de comunicação de massa e o sistema político, no estudo de campanhas eleitorais sobre as quais ele adquiriu experiência, incluindo pesquisa comparativa. Ele é o terceiro autor mais citado do mundo no campo de estudos comparativos sobre comunicação política. O professor Mancini integra o Comitê Científico da Revista Famecos desde 2017.
} 
Revista Famecos - No contexto da comunicação pública, qual seria a alternativa para os indivíduos mais pobres que não têm acesso à internet? A televisão pública ainda pode ser uma ferramenta necessária?

Paolo Mancini - Na presente condição de abundância do sistema midiático o destino da televisão pública não é nem claro nem garantido. Não nos esqueçamos de que a televisão pública nasceu e se desenvolveu em um sistema de escassez de mídia, que justificou e tornou necessária a intervenção do poder público para garantir a universalidade. A sua sobrevivência, certamente, poderá realizar muitas das funções que hoje são prerrogativa de outros instrumentos, mas repito, o seu futuro não é certo.

Revista Famecos - Sendo a internet uma excelente ferramenta no processo participativo de cidadania, o senhor acredita que a sociedade de hoje está consciente desse poder?

Paolo Mancini - Sim, de acordo com os fatos ela está. Todos hoje percebem que podem descobrir tantas coisas que antes eram inatingíveis. Logo, os cidadãos podem descobrir e reagir de acordo com essa realidade. Ela está representada no poder de todos os usuários da internet de hoje e acredito que eles tenham consciência.

Revista Famecos - E de que forma essa grande quantidade de informação nas redes pode favorecer a divulgação dos dados públicos servindo como uma ferramenta para a democracia?

Paolo Mancini - Isso também faz parte da vida. As administrações públicas são forçadas a publicar seus dados. Outras organizações têm a possibilidade de acessá-los e fazer circular a informação através da rede. Basta citar o exemplo de muitas organizações que disponibilizam informações sobre quais deputados votaram a favor ou contra uma determinada lei etc. Repito que a internet torna "o segredo" algo quase impossível. É claro que ainda existem limitações e tentativas de censura; o enorme poder das plataformas digitais é uma realidade, mas espaços antes impensáveis e oportunidades para o público se abriram. Os problemas mudam, soluções são encontradas, mas logo nascem novas dificuldades. Para a administração pública se aplica o mesmo critério utilizado no comércio on-line: os indivíduos podem acessar diretamente os serviços "sem pedir permissão". Se a administração pública não colocar os seus dados na web, se for rejeitada pelos cidadãos através do voto, outra pessoa realizará essa tarefa em seu lugar. Obviamente isso se aplica às sociedades democráticas.

Revista Famecos - Em sua opinião quais são as principais dificuldades em adotar transparência na comunicação pública promovida pelos governos?

Paolo Mancini - Existem dois problemas. Um deles está, indubitavelmente, ligado à tentativa de encerrar as administrações públicas dentro de suas conchas para impedir que os cidadãos saibam coisas que, de acordo com determinada lógica, não precisam saber. Em suma, adota-se a lógica do sigilo, que, ao contrário da transparência, é utilizada precisamente para esconder. 
O segundo problema é de natureza cultural: a cultura da transparência está lutando para se manter; o processo de abertura dos dados públicos não é um hábito, não tanto pela tentativa explícita de esconder os dados, mas porque os políticos, gestores e administradores não estão acostumados a lidar com a transparência.

Revista Famecos - Essa fragmentação também se reflete no campo da comunicação política?

Paolo Mancini - Por que eu falo sobre fragmentação? Porque tem havido um aumento na quantidade de fontes de informação disponíveis, cada uma dirigida a um nicho público específico, gerando opiniões diferentes e particulares.

Há uma fragmentação, ou seja, os nichos de cada público estão fechados em si mesmos dificultando o diálogo com outros nichos. Na Itália, os nichos públicos sempre existiram: os que votam à esquerda leem os jornais de esquerda, assistem à televisão de esquerda, enquanto os eleitores de direita leem os jornais de direita e assistem à televisão de direita. O que a internet fez foi aumentar essa polarização, mas sem mudar as preferências políticas tradicionais daqueles que votam na direita ou na esquerda. A internet não mudou esse relacionamento. Da mesma forma, por vezes a fragmentação não está baseada em posições políticas, mas nas opiniões que cada um tem sobre seus temas de interesse. Por exemplo, em nossa pesquisa (MANCINI; HALLIN, 2004), demonstramos que aqueles que têm uma opinião negativa sobre a Europa tendem a interagir com aqueles que têm a mesma opinião, e assim por diante. Dessa forma, construímos algo que Cass Sunstein chamou de "câmaras de eco", que envolve os cidadãos em nichos de discussão com pessoas da mesma opinião. As opiniões já compartilhadas são assim fortalecidas e a polarização política é aumentada.

Revista Famecos - Em Il post-partito (MANCINI, 2015), o senhor explica a diferença entre o populismo como ideologia e estilo populista, na medida em que o candidato se aproxima dos cidadãos por meio da comunicação direta ao conhecer os seus interesses. Trata-se de uma nova maneira de fazer política?

Paolo Mancini - Por que eu prefiro usar o termo estilo populista? Porque hoje o líder político que fala na internet ou na televisão sabe que não fala apenas com pessoas politizadas ou com membros de um partido político. Ele fala com todos!

Hoje, há uma parte do mundo que está preocupada em atacar o populismo. Acredito que ao falar diretamente com cada eleitor o político abre uma nova alternativa comunicativa que Ihe permite interagir diretamente, sem a intermediação tradicional. O que chamei de apelo direto significa a forma com que o político se adapta às ideias, à linguagem e aos valores já compartilhados pelo cidadão. Assim, ele passa a adotar um estilo que chamamos populista. Yves Mény afirma que seremos forçados a viver com o populismo. Seremos forçados a conviver com essa realidade, como afirma Mény, uma vez que as novas possibilidades de relação direta com o cidadão estão tornando desnecessário o uso dos intermediários tradicionais 
cada vez mais deveremos nos adaptar à linguagem da vida cotidiana, "a linguagem das ruas". Isso é populismo? Não necessariamente. Em minha opinião, é um estilo que vem se formando devido à disponibilidade de novos espaços, onde o candidato sabe que deve usar gestos e linguagem facilmente assimiláveis. Quando fala diretamente com o cidadão, o político está ciente de que ele fala com todos, politizados ou não, logo, ele deve adotar um comportamento entendido por todos. O importante é saber se esse estilo populista será refletido em suas decisões subsequentes.

Revista Famecos - Considerando a estrutura atual dos partidos políticos, quais são os riscos do processo sem o uso da comunicação tradicional?

Paolo Mancini - Existem riscos de banalização e, certamente, da perda de capacidade pedagógica e evolutiva no processo de politização. Com o apelo direto, os políticos tendem a referendar as opiniões mais difundidas, de simples aceitação, reduzindo, dessa forma o necessário processo de amadurecimento, fruto do debate político.

Revista Famecos - Esse apelo direto significará o fim dos partidos políticos?

Paolo Mancini - Aqui temos uma contradição. Os partidos políticos de massa tradicionais como os conhecemos estão terminando porque o formato de sua comunicação mudou. A internet e, em particular, as mídias sociais permitiram que os mesmos políticos se comunicassem com os cidadãos por meio do apelo direto, independentemente das antigas estruturas tradicionais de mediação. O pós-partido é algo novo com o qual devemos conviver se considerarmos o espaço político como um ambiente de comunicação pública, uma arena competitiva e diversificada como hoje. Essa é a contradição! O antigo acabou e precisamos inventar o novo. Os partidos políticos que conhecemos até hoje não são mais possíveis. A nova forma de fazer política baseia-se na elaboração de políticas públicas, através da contribuição de uma rede participativa de indivíduos mais especializados. A obrigação dos partidos políticos é organizar e trabalhar nessas especializações em benefício da sociedade. A internet mudou o sistema de circulação de informações que não mais pertencem às estruturas e hierarquias dos partidos, elas estão disponíveis a todos aqueles que podem acessá-la. Ao mesmo tempo, os partidos políticos ainda são necessários. Eles são necessários para a organização do trabalho parlamentar, como local para a produção de ideias e definição de políticas públicas. É a partir do debate, do apoio dos membros das organizações partidárias que poderão nascer políticas mais completas e que correspondam às necessidades da sociedade.

Revista Famecos - O que o senhor sabe sobre o Brasil, um país emergente de tamanho continental, mas com alto índice de analfabetismo e pouco acesso a ferramentas sociais disponíveis? O que pode ser feito para melhorar o processo de comunicação pública?

Paolo Mancini - O Brasil é um território gigantesco com concentrações impressionantes de mídia, como a Rede Globo. Algo que não existe na Itália. Uma organização do tamanho da 
Rede Globo não é comparável, nem mesmo, ao império de Berlusconi. Partindo de um ponto de vista econômico, temos uma grande concentração de riqueza em um imenso espaço territorial. Um país enorme como o Brasil, com uma enorme concentração populacional desigualmente distribuída em seu território desenvolveu um modelo de comunicação diferente daquele desenvolvido na Europa. Certamente, é necessário considerar a situação das comunidades locais e suas identidades. O jornalismo não nasce no vazio, a mídia não nasce no vazio. Dentro deles estão algumas condições culturais, políticas, históricas e até geográficas; isso acontece no Brasil como no resto do mundo. Carey escreveu que os Estados Unidos são um país construído sobre a comunicação. Desde sua independência, os Estados Unidos compreenderam que para se comunicar no enorme território em que se estendiam era necessário criar estradas, ferrovias, linhas telefônicas e depois desenvolver o rádio e a televisão. Na Europa foi diferente. Essas necessidades não existiam na criação de pequenos países europeus, todos muito próximos. O caso do Brasil é muito parecido com o dos Estados Unidos, a comunicação é a espinha dorsal do país.

Revista Famecos - E sobre a eleição de Jair Bolsonaro que chegou a presidência do Brasil se utilizando largamente das redes sociais?

Paolo Mancini - Sobre Bolsonaro eu sei pouco. Eu sei o que eu li nos jornais. Se ele ganhou, como ganhou Donald Trump, graças também às oportunidades das redes sociais e do Twitter, em particular, então se abre uma era diferente, onde, provavelmente, o Twitter será substituído pelas decisões concretas que ele será forçado a tomar ao longo do tempo. Governo é comunicação são coisas diferentes.

Revista Famecos - Como senhor imagina o futuro da comunicação política?

Paolo Mancini - Eu tenho uma perspectiva positiva. De uma parte, a democracia será mais forte porque será cada vez mais participativa, mas de outra, estará sujeita a um processo de enfraquecimento, como afirmou John Thompson, a publicidade amplia a visibilidade dos líderes e das instituições políticas, mas os torna mais fracos devido, exatamente, a sua transparência. Todas as distorções da democracia que antes estavam ocultas, porque não podiam ser vistas, estão agora expostas a todos, ampliando a sua possibilidade de controle. Um aumento no controle gerado pela capacidade que cada cidadão tem de verificar as imagens, as ações e as declarações dos políticos. Portanto, a visibilidade do político aumentada pela exposição na mídia pode destacar seus pontos fortes, mas também os frágeis, trabalhando contra sua própria imagem, contra seus próprios interesses. Sim, agora o rei está nu! ${ }^{3}$ Apesar do desenvolvimento da comunicação, o rei está nu. E então o rei esta mais enfraquecido e mais exposto à opinião pública. Eis uma das razões para o desinteresse dos cidadãos pela política: o aumento da transparência torna os detentores do poder expostos aos olhos de todos aqueles, que com

3 O autor faz referência a obra A roupa nova do rei, conto de autoria Hans Christian Andersen, publicado em 1837. 
maior força, agora, podem controlá-los. A democracia se torna frágil porque oferece a todos a oportunidade de controlar; é mais forte porque há mais controle, mas o controle revela tudo o que permaneceu oculto até alguns anos atrás.

\section{Referências}

MANCINI, Paolo. II post partito. La fine delle grandi narrazioni. Bolonha: II Mulino Editore, 2015.

MANCINI, Paolo. Perché comunicazione pubblica? Le ragioni sociali di uno sviluppo impetuoso. Quaderni di Sociologia, Torino, n. 30, 2002. Disponível em: http://journals. openedition.org/qds/1232. Acesso em: 15. jun. 2012. https://doi.org/10.4000/qds.1232

MANCINI, Paolo; HALLIN, Daniel. Modelli di giornalismo: mass media e politica nelle democrazie occidentali. Roma-Bari: Laterza, 2004.

\section{Dados do entrevistador:}

\section{Fernando Biffignandi - biffignandi@yahoo.com}

Arquiteto e Urbanista graduado pelo Centro Universitário Uniritter (1987) Mestre em Comunicação Social pela Pontifícia Universidade Católica do Rio Grande do Sul (2013), Doutor em Comunicação Social pela Pontifícia Universidade Católica do Rio Grande do Sul (2018), atualmente cursando o Pós-Doutorado na Universidade de Coimbra em Portugal. Linha de pesquisa voltada à Comunicação Pública focada nos seguintes temas: Comunicação dirigida à habitação de interesse social, comunicação social, Folkcomunicação, Educomunicação e metodologia de projeto. Atualmente trabalha como Arquiteto e Urbanista no Departamento Municipal de Habitação da Prefeitura de Porto Alegre.

\section{Endereço do autor:}

Departamento Municipal de Habitação da Prefeitura de Porto Alegre Av. Princesa Isabel, 1115 - Azenha, Porto Alegre (RS) - Brasil 